\title{
Bioartificial pleura using allogenic cell sheet for closing of lung air leakage
} \author{
Japan

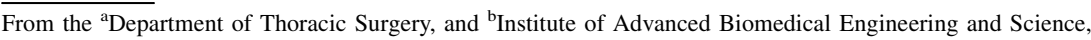 \\ Tokyo Women's Medical University, Tokyo, Japan. \\ Supported by Creation of Innovation Centers for Advanced Interdisciplinary Research Areas Program in the Proj- \\ ect for Developing Innovation Systems Cell Sheet Tissue Engineering Center from the Ministry of Education, \\ Culture, Sports, Science and Technology, Japan. \\ Disclosures: Dr Yamato has equity financial interest in CellSeed, a publicly traded Japanese biotechnology com- \\ pany exclusively developing cell sheet technology for regenerative medicine purposes. All other authors re- \\ ported no conflicts of interest. \\ The Journal policy requires editors and reviewers to disclose conflicts of interest and to decline handling or re- \\ viewing manuscripts for which they may have a conflict of interest. The editors and reviewers of this article \\ have no conflicts of interest. \\ Received for publication Sept 17, 2020; accepted for publication Sept 18, 2020; available ahead of print Sept 25, \\ 2020. \\ Address for reprints: Masato Kanzaki, MD, Department of Thoracic Surgery, Tokyo Women's Medical Univer- \\ sity, 8-1 Kawada-cho, Shinjuku-ku, Tokyo 162-8666, Japan (E-mail: kanzaki.masato@ @wmu.ac.jp). \\ JTCVS Techniques 2020;4:336-40 \\ 2666-2507 \\ Copyright $\odot 2020$ The Authors. Published by Elsevier Inc. on behalf of The American Association for Thoracic \\ Surgery. This is an open access article under the CC BY-NC-ND license (http://creativecommons.org/licenses/by- \\ nc-nd/4.0/). \\ https://doi.org/10.1016/j.xjtc.2020.09.024
}

Masato Kanzaki, MD, ${ }^{\mathrm{a}, \mathrm{b}}$ Hidekazu Sekine, $\mathrm{PhD},{ }^{\mathrm{b}}$ Ryo Takagi, $\mathrm{PhD},{ }^{\mathrm{b}}$ and Masayuki Yamato, $\mathrm{PhD},{ }^{\mathrm{b}}$ Tokyo,

Video clip is available online.

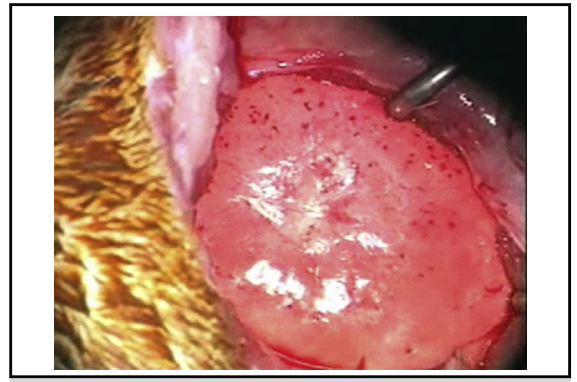

Transplanted allogenic cell sheets can prevent persistence pulmonary air leaks.

\section{CENTRAL MESSAGE}

Because the ACSs used to close

PALs survived on the lung sur-

face for at least 7 days, trans-

planted ACSs can prevent

See Commentaries on pages 341 and 343 . persistence PALS.
Pulmonary air leaks (PALs) caused by pleural injury is difficult to avoid in pulmonary surgery. ${ }^{1}$ We previously reported intraoperative PAL closure with an autologous cell sheet (CS) for ensuring permanent closure (Appendix 1 and Video 1). ${ }^{2,3}$ Clinical application of autologous CS is limited by production difficulties. For spreading this technique more widely and expanding the use of CS to patients with acute surgical needs, this study investigated allogenic CSs. All procedures were performed in accordance with the National Institutes of Health Guide for the Care and Use of Laboratory Animals and the Guidelines of Tokyo Women's Medical University on Animal Use.

Lung derived cells (LDCs) were isolated from the lungs of 1-day-old firefly luciferase-expressing Lewis neonatal rats. Finely minced lung tissues were dissociated with $0.05 \%$ collagenase at $37^{\circ} \mathrm{C}$ for 10 minutes. Suspensions containing cells were then centrifuged, resuspended in fresh collagenase, and repeated the same procedure another 3 times. Obtained LDCs were plated at an initial density of $2 \times 10^{5}$ cells $/ \mathrm{cm}^{2}$ on a $60-\mathrm{mm}$ diameter culture dish and cultured for 7 days at $37^{\circ} \mathrm{C}$ in a $5 \%$ carbon dioxide humidified atmosphere, and the culture medium was changed

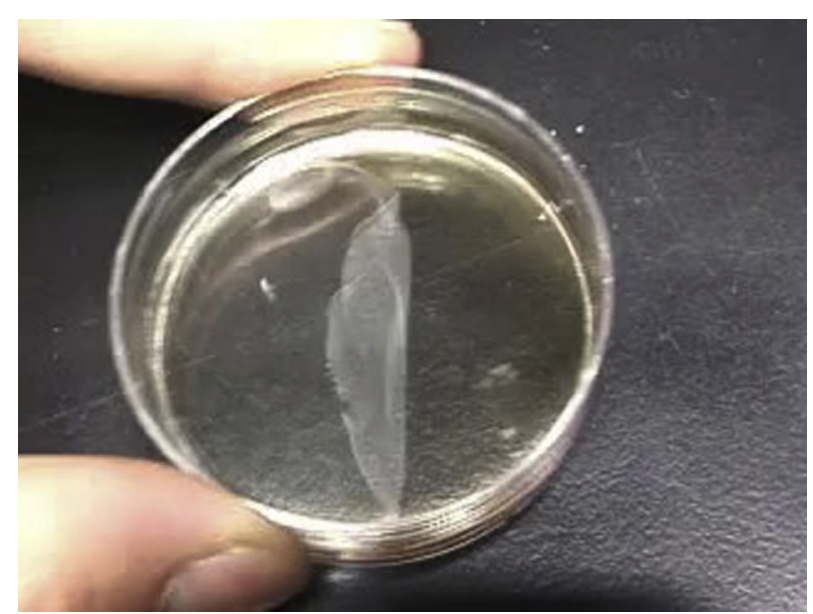

VIDEO 1. Cell sheet engineering. Under normal culture conditions at $37^{\circ} \mathrm{C}$, various types of cells can attach, spread, and proliferate on these surfaces, similar to cells on ordinary tissue culture dishes. ${ }^{4-8}$ However, by simply reducing the culture temperature to $20^{\circ} \mathrm{C}$, the cultured cells with their deposited extracellular matrix (ECM) can be noninvasively harvested as intact sheets without the need for proteolytic enzymes. Video available at: https://www.jtcvs.org/article/S2666-2507(20)30544-7/ fulltext. 

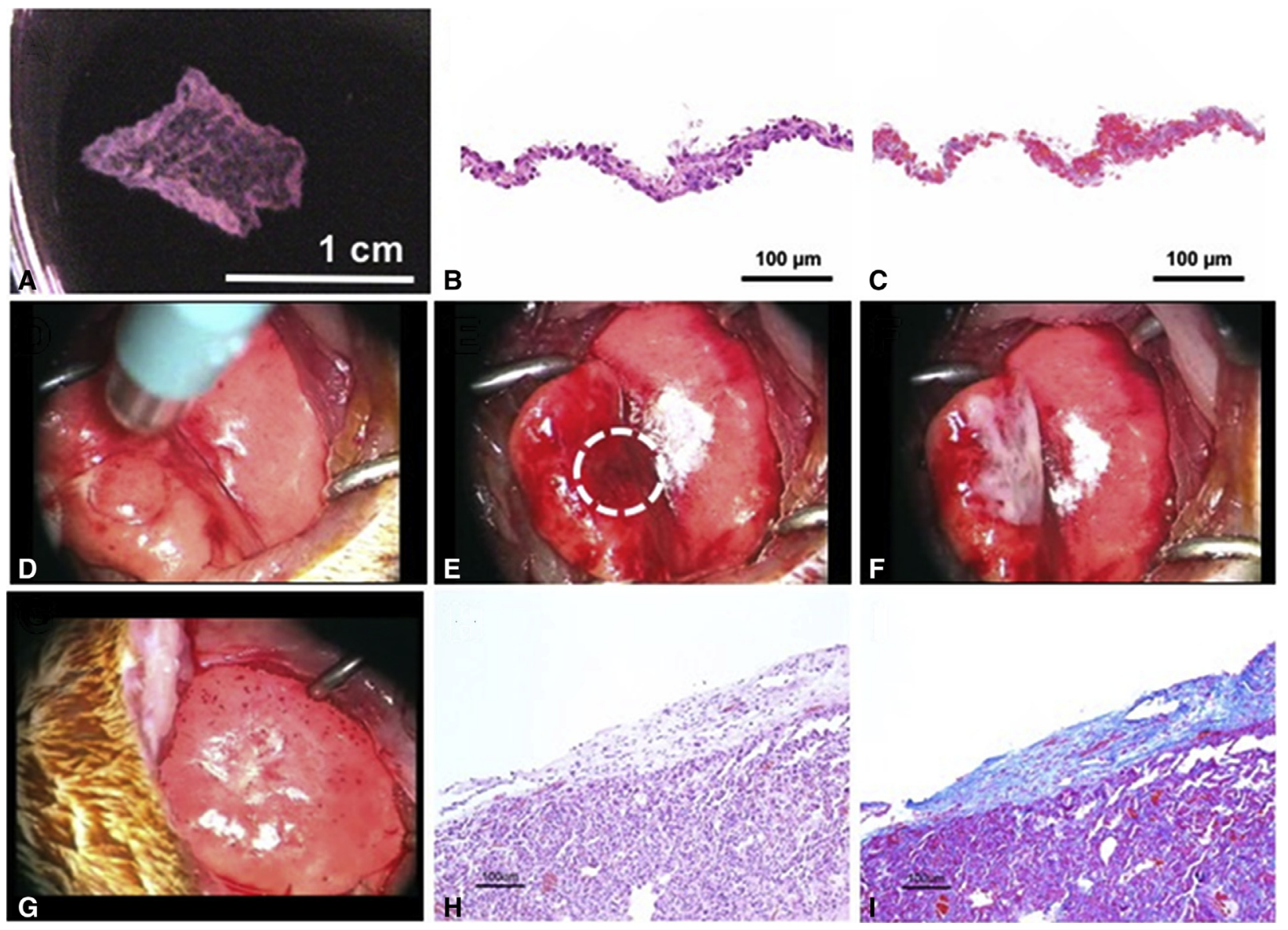

FIGURE 1. Preparation of allogenic cell sheet (ACS), transplantation of ACS to close pleural injury, and transplanted ACS after 4 weeks. A, ACS was harvested by a simple temperature reduction to $20^{\circ} \mathrm{C}$ without requiring proteolytic enzymes. Cultured cells can be noninvasively separated along their deposited extracellular matrix (ECM) from a culture dish as an intact sheet. During the spontaneous cell detachment process, ACSs slightly shrink due to cytoskeletal re-organization. Harvested ACS can be re-extended by external force with maintaining their function and intact structures. B, Hematoxylin and eosin (HE) staining of harvested ACS consisting of 2 to 4 stratified cell-dense layers. C, Azan staining of harvested ACS that was confirmed to have a small amount of ECM. D, Transplantation of ACS onto the surface of lung to close pleural injury. For pleural injury, the extent of resection was marked on the left lung with a biopsy punch. E, A $5 \times 2$-mm incision marked by the white dotted circle was created in the left lung by surgical scissors. F, Pleural injury was closed with the transplantation of ACS. G, At 28 days after surgery, ACS was confirmed to adhere to the lung surface. H, At 28 days after surgery, HE staining of transplanted ACS, which was found to adhere tightly to the lung surface. I, Azan staining of transplanted ACS, which was confirmed to have the sufficient amount of secreted ECM.

every 2 days. At 7 days after being treated with $0.05 \%$ trypsin-ethylenediaminetetraacetic acid for 5 minutes at $37^{\circ} \mathrm{C}$, LDCs were harvested, subsequently dissociated with $0.05 \%$ trypsin-ethylenediaminetetraacetic acid, seeded on a 24-mm square-patterned temperature-responsive dish at a density of $2 \times 10^{5}$ cells $/ \mathrm{cm}^{2}$, and cultured for additional 7 days. After being incubated at $20^{\circ} \mathrm{C}$, LDCs were harvested as a CS (Figure 1, A), which shrank and had 2 to 4 cell layers with slight extracellular matrix (ECM) (Figure 1, $B$ and $C$ ).

For transplantation, F-344 athymic $(\mathrm{n}=4)$ and Brown Norway $(\mathrm{BN})$ rats $(\mathrm{n}=4)$ were anaesthetized with $2 \%$ inhaled isoflurane under mechanical ventilation. Rats were positioned in the right lateral decubitus position, and a left-lateral thoracotomy was performed. Based on a rat air leak model reported previously, a $5 \times, 2$-mm incision was created by surgical scissors for making pleural injury (Figure 1, $D$ and $E$ ), which was confirmed by observing air bubbles from the lung. ${ }^{4}$ Pleural injury was successfully closed with the transplantation of CS (Figure 1, F, and Video 2) in all animals, and due to difficulty in managing chest tube drainage in rats, no chest tubes were placed. After transplantation, no immunosuppressants were used in both groups. To investigate the cell viabilities of luciferase expressing CSs, CS transplanted rats were anaesthetized in the same fashion at postoperative days (PODs) 7 and 14, 

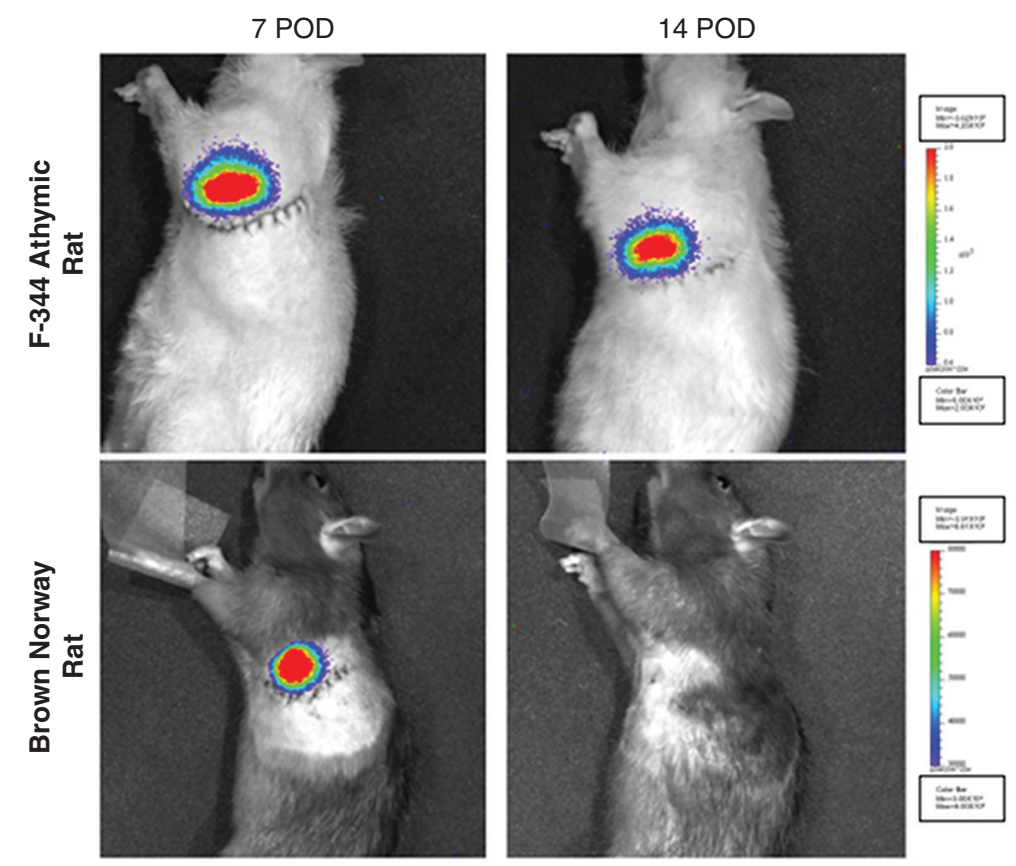

A

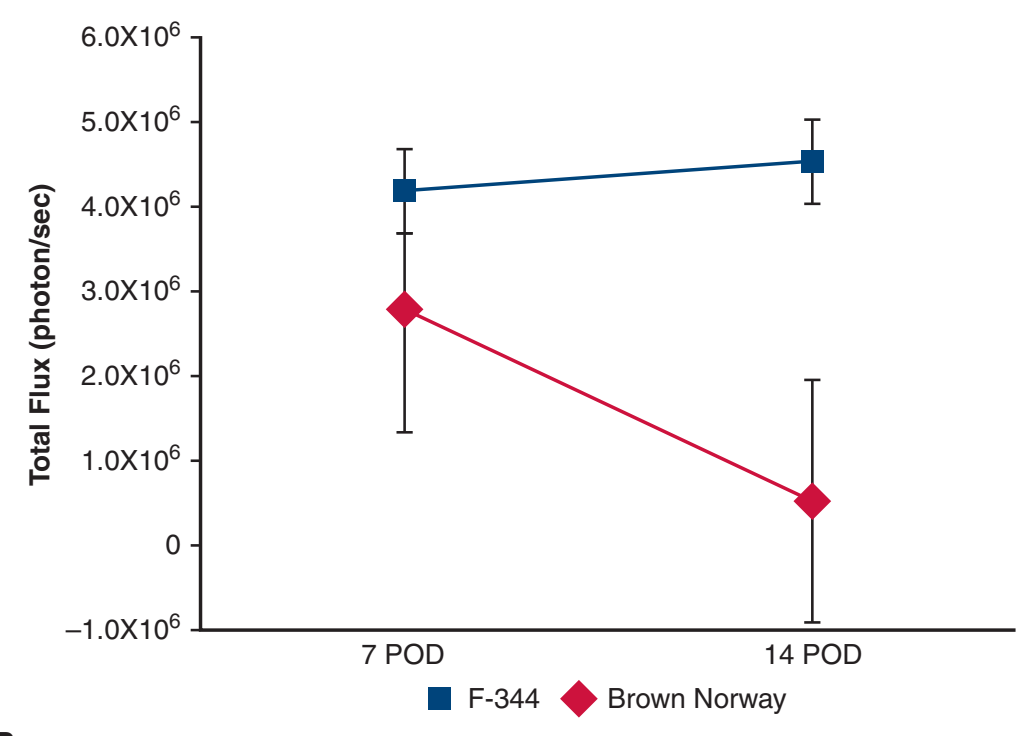

B

FIGURE 2. Bioluminescence images of transplanted allogenic cell sheet (ACSs) in rats. A, Typical images show luminescence signals emitted from luciferase-expressing cell sheets transplanted in F-344 athymic rat at 7 postoperative days (POD) and 14 POD, and Brown Norway (BN) rat at 7 POD and 14 POD. Compared with the athymic rats, BN rats showed a lower intensity at 14 POD. The viability of cell sheet in the athymic rats was higher than that of BN rats at 14 POD. The upper and lower columns of images represent F-344 athymic rat and BN rat, respectively. B, The graph shows changes in photon flux emitted from ACSs in the thoracic cavity, and the flux indicates the luminescence signal intensity. A dynamic change in the intensities of both rats is clearly shown by the numerical data. At $7 \mathrm{POD}$ and $14 \mathrm{POD}$, mean \pm standard deviation photon flux values were $4.17 \pm 1.88$ to $4.53 \pm 2.03 \times 10^{6}$ photon/sec in athymic rats and $2.79 \pm 1.43$ to $0.53 \pm 0.49 \times 10^{6} \mathrm{photon} / \mathrm{sec}$ in $\mathrm{BN}$ rats, respectively. Although there were no significant differences in intensities between both groups, the differences between athymic rats and BN rats increased from 7 POD to 14 POD. BN rats had a larger decrease in the photon flux value than the athymic rats at 14 POD.

and $150 \mathrm{mg} / \mathrm{kg}$ D-luciferin firefly potassium was injected into the dorsalis penis vein 15 minutes before imaging analysis with an in vivo bioluminescence imaging system.
Bioluminescence images showed dynamic changes in the intensity for both rats at POD 7 and POD 14 (Figure 2, A). Compared with the athymic rats, $\mathrm{BN}$ rats seemed to 


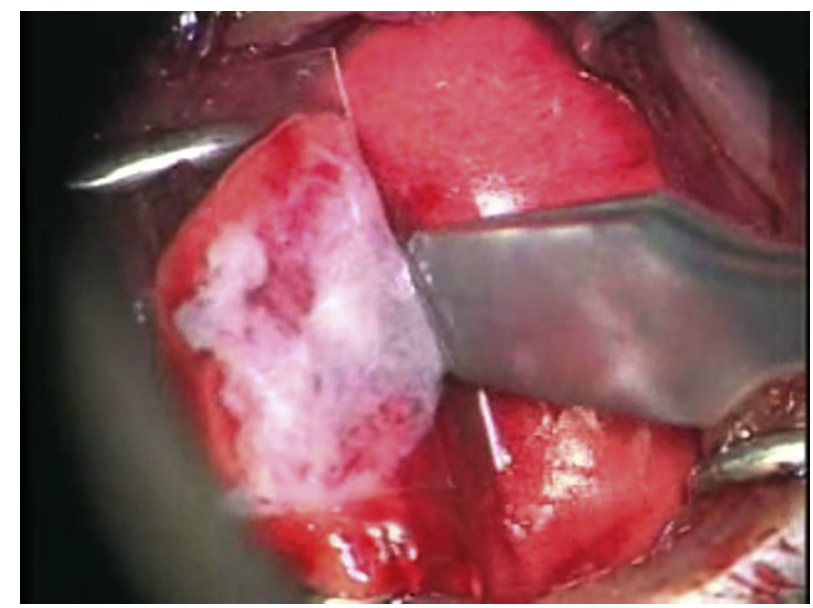

VIDEO 2. Transplantation of cell sheet. All rats were anesthetized with $2 \%$ inhaled isoflurane under mechanical ventilation. The animals were positioned in a right lateral decubitus position, and a left-lateral thoracotomy in the fifth intercostal space was performed. A 5-mm-long incision with a depth of $2 \mathrm{~mm}$ was made in the left lung by sterile surgical scissors. To avoid pleural adhesions after thoracotomy, a pleural injury was created at the apex of the lung. Air leakage was confirmed by the intermittent appearance of air bubbles after the initial injury. Pleural injury was closed by transplanting of an allogenic cell sheet harvested by simply reducing the culture temperature to $20^{\circ} \mathrm{C}$. Video available at: https://www.jtcvs.org/ article/S2666-2507(20)30544-7/fulltext.

show a lower intensity at POD 14 . A dynamic change in the intensities was clearly shown by the numerical data where the mean \pm standard deviation intensities of the athymic rats at POD 7 and POD 14 were $4.17 \pm 1.88$ and $4.53 \pm 2.03 \times 10^{6}$, and those of BN rats at POD 7 and POD 14 were $2.79 \pm 1.43$ and $0.53 \pm 0.49 \times 10^{6}$ photons/second, respectively (Figure 2, B). The differences between athymic and BN rats increased from POD 7 to POD 14 , and the athymic rats showed a higher cell viability than $\mathrm{BN}$ rats at POD 14. All animals survived for the follow-up period. The thoracic cavity was reopened at POD 28 , and the transplanted CS was observed to attach to the lung surface (Figure 1, G). After the left lung was resected, the transplanted CS adhered tightly to the lung, and ECM increased inside CS (Figure 1, $H$ and $I$ ).

Although most PALs disappear within 2 to 3 PODs, approximately $5 \%$ to $10 \%$ of patients continue to have PALs after POD 5. ${ }^{4}$ For performing intraoperative PAL closure, various biological sealants are used, resulting in marginal success due to their poor adhesive stability, biocompatibility, and inflexibility. ${ }^{5}$ Although autologous CS is used as a durable long-term PAL sealant, a long culture period for creating CS is a problem. After being closed with short-life adhesives or materials, postoperative PALs disappear within several days, requiring no long-life materials, and this study focused on allogeneic CSs. Although transplanted allogenic CSs could be rejected by immune response, the transplanted CS survived on the lung surface at least 7 days without immunosuppressants with rich ECM. Additionally, transplated allogeneic CSs closed PALs in all the animals. Allogeneic CSs may be an alternative to autologous CSs for closing PALs.

The authors thank Professor Eiji Kobayashi (Department of Organ Fabrication, Keio University School of Medicine) for kindly supplying firefly luciferase-expressing Lewis neonatal rats.

\section{References}

1. Attaar A, Winger DG, Luketich JD, Schuchert MJ, Sarkaria IS, Christie NA, et al A clinical prediction model for prolonged air leak after pulmonary resection. $J$ Thorac Cardiovasc Surg. 2016;153:690-9.

2. Kanzaki M, Yamato M, Yang J, Sekine H, Takagi R, Isaka T, et al. Functiona closure of visceral pleural defects by autologous tissue engineered cell sheets. Eur J Cardiothorac Surg. 2008;34:864-9.

3. Kanzaki M, Takagi R, Washio K, Kokubo M, Yamato M. Bio-artificial pleura using an autologous dermal fibroblast sheet. NPJ Regen Med. 2017;2:26.

4. Kanzaki M, Yamato M, Yang J, Sekine H, Kohno C, Takagi R, et al. Dynamic sealing of lung air leaks by the transplantation of tissue engineered cell sheets. Biomaterials. 2007; 28:4294-302.

5. Aldaghlawi F, Kurman JS, Lily JA, Hogarth K, Donington J, Ferguson MK, et al. A systematic review of digital vs analog drainage for air leak after surgical resection or spontaneous pneumothorax. Chest. 2020;157:1346-53. 


\section{APPENDIX 1: CELL SHEET ENGINEERING}

Cell sheet engineering uses temperature-responsive culture dishes. ${ }^{1}$ By covalently grafting a temperatureresponsive polymer, poly( $\mathrm{N}$-isopropylacrylamide), the surfaces of conventional culture dishes, various types of cells can be cultures on the dishes and harvested as cell monolayers by simply reducing the incubation temperature instead of typical proteolytic harvest methods. ${ }^{2,3}$

Under normal culture conditions at $37^{\circ} \mathrm{C}$, various types of cells can attach, spread, and proliferate on these surfaces, similar to cells on ordinary tissue culture dishes. ${ }^{4-8}$ However, by simply reducing the culture temperature to $20^{\circ} \mathrm{C}$, the cultured cells with their deposited extracellular matrix can be noninvasively harvested as intact sheets without the need for proteolytic enzymes (Video 1). ${ }^{9}$ During these spontaneous cell detachment processes, cell sheets slightly shrink due to cytoskeletal reorganization but can re-expand by external force while maintaining their functions and intact structures. Because extracellular matrix is maintained on the basal surfaces of the cell sheets, they can stably attach to other surfaces.

\section{References}

1. Yamato M, Okano T. Cell sheet engineering. Mater Today. 2004;7:42-7.

2. Hirose M, Kwon OH, Yamato M, Kikuchi A, Okano T. Creation of designed shape cell sheets that are noninvasively harvested and moved onto another surface. Biomacromolecules. 2000;1:377-81.

3. Yamato M, Okuhara M, Karikusa F, Kikuchi A, Sakurai Y, Okano T. Signal transduction and cytoskeletal reorganization are required for cell detachment from cell culture surfaces grafted with a temperature-responsive polymer. J Biomed Mater Res. 1999;44:44-52.

4. Shimizu T, Yamato M, Kikuchi A, Okano T. Two-dimensional manipulation of cardiac myocyte sheets utilizing temperature-responsive culture dishes augments the pulsatile amplitude. Tissue Eng. 2001;7:141-51.

5. Nishida K, Yamato M, Hayashida Y, Watanabe K, Yamamoto K, Adachi E, et al. Corneal reconstruction with tissue-engineered cell sheets composed of autologous oral mucosal epithelium. N Engl J Med. 2004;351:1187-96.

6. Shimizu T, Yamato M, Isoi Y, Akutsu T, Setomaru T, Abe K, et al. Fabrication of pulsatile cardiac tissue grafts using a novel 3-dimensional cell sheet manipulation technique and temperature-responsive cell culture surfaces. Circ Res. 2002;90: e40-8.

7. Shiroyanagi Y, Yamato M, Yamazaki Y, Toma H, Okano T. Transplantable urothelial cell sheets harvested noninvasively from temperature-responsive culture surfaces by reducing temperature. Tissue Eng. 2003;9:1005-12.

8. Hasegawa M, Yamato M, Kikuchi A, Okano T, Ishikawa I. Human periodontal ligament cell sheets can regenerate periodontal ligament tissue in an athymic rat model. Tissue Eng. 2005;11:469-78.

9. Yang J, Yamato M, Shimizu T, Sekine H, Ohashi K, Kanzaki M, et al. Reconstruction of functional tissues with cell sheet engineering. Biomaterials. 2007;28:5033-43. 